\title{
The provision of nutritional advice and care for cancer patients: a UK national survey of healthcare professionals
}

\author{
Jane L. Murphy ${ }^{1}$ (D) $\cdot$ Fehmidah Munir $^{2}$ (D) $\cdot$ Fiona Davey $^{3} \cdot$ Laura Miller $^{4,5}$ (D) Ramsey Cutress $^{6}$ (D) Rhys White $^{7}$. \\ Megan Lloyd ${ }^{6}$ (D) $\cdot$ Justin Roe R,9,10 $^{8} \cdot$ Carol Granger $^{11}$ (D) $\cdot$ Sorrel Burden ${ }^{12}$ (D) Lesley Turner $^{3}$
}

Received: 9 July 2020 / Accepted: 1 September 2020 / Published online: 12 September 2020

(C) The Author(s) 2020

\begin{abstract}
Purpose People living with and beyond cancer often experience nutrition-related issues and should receive appropriate advice on nutrition that is consistent and evidence based. The aim of this study was to investigate current practice for the provision of nutritional care by healthcare professionals (HCPs) from a UK national survey produced by the National Institute for Health Research (NIHR) Cancer and Nutrition Collaboration.

Methods An online survey sent to professional groups and networks included questions on discussing nutrition, providing information, awareness of guidelines, confidence in providing nutritional advice, training and strategies for improving nutritional management.

Results There were 610 HCPs who responded including nurses (31\%), dietitians (25\%), doctors (31\%) and speech and language therapists (9\%). The majority of HCPs discusses nutrition (94\%) and provides information on nutrition (77\%). However, only $39 \%$ of HCPs reported being aware of nutritional guidelines, and just $20 \%$ were completely confident in providing nutritional advice. Awareness of guidelines varied between the different professional groups with most but not all dietitians reporting the greatest awareness of guidelines and GPs the least $(p=0.001)$. Those HCPs with a greater awareness of guidelines had received training $(p=0.001)$ and were more likely to report complete confidence in providing nutritional advice $(p=0.001)$.

Conclusion Whilst HCPs discuss nutrition with cancer patients and may provide information, many lack an awareness of guidelines and confidence in providing nutritional advice. To ensure consistency of practice and improvements in patient care, there is scope for enhancing the provision of appropriate nutrition education and training.
\end{abstract}

Keywords Cancer $\cdot$ Nutrition $\cdot$ Healthcare professional $\cdot$ Nutritional advice $\cdot$ Guidelines $\cdot$ Survey

Jane L. Murphy

jmurphy@bournemouth.ac.uk

1 Faculty of Health \& Social Sciences, Bournemouth University, $10 \mathrm{St}$ Paul's Lane, Bournemouth BH8 8AJ, UK

2 School of Sport, Exercise \& Health Sciences, Loughborough University, Loughborough, UK

3 NIHR Cancer and Nutrition Collaboration, University Hospital Southampton NHS Foundation Trust, Southampton, UK

4 Nutrition and Dietetics Department, Nottingham University Hospitals NHS Trust, Nottingham, UK

5 NIHR Nottingham BRC, Nottingham, UK
6 University Hospital Southampton NHS Foundation Trust, Southampton, UK

7 Nutrition and Dietetics, Guys and St Thomas' NHS Foundation Trust, London, UK

8 The Royal Marsden NHS Foundation Trust, London, UK

9 Imperial College Healthcare NHS Trust, London, UK

10 Imperial College, London, UK

11 Penny Brohn Cancer Care, Bristol, UK

12 School of Health Sciences, University of Manchester, Manchester, UK 


\section{Background}

Nutrition is an important determinant of well-being for people living with and beyond cancer, affecting response to therapy and preventing secondary recurrence of cancer and development of other non-communicable diseases $[1,2]$. With increased numbers of people being diagnosed and surviving cancer in the UK [3], access to appropriate dietary advice and care is part of the NHS England National Cancer Strategy supported by the NHS in England [4]. International guidelines recommend that cancer patients receive tailored nutrition advice from trained healthcare professionals (HCPs) appropriate for the cancer site, their nutritional status and treatment toxicity [5]. The importance of the 'teachable moment' has been described following a diagnosis as an opportunity for individuals to change undesirable diet-related behaviours and adopt risk reducing strategies and manage symptoms [6]. As people living beyond a cancer diagnosis are reported to change eating habits [7], there may be multiple teachable moments throughout a patient's care journey. This is at a time when individuals are susceptible to receive information from less trusted sources such as the Internet that can increase confusion and anxiety. Therefore, it is crucial that healthcare professionals are able to provide appropriate and consistent advice on nutrition-related issues [8].

However, not all people living with and beyond cancer receive professional advice about nutrition and diet including those who are at risk of malnutrition [5] or people who are diagnosed with cancer and complete treatment [9]. Whilst nutritional advice is valued by people following a cancer diagnosis, they have reported that advice received by healthcare professionals has been inconsistent [10-12].

Oncologists may not reliably identify those at nutritional risk due to lack of knowledge and training, awareness of guidelines, time constraints and lack of standardised protocols for care [13, 14]. The lack of awareness and consideration of nutritional issues was reported in a recent survey of Italian oncologists [15]. A UK survey of specialist nurses, clinicians, surgeons and allied health professionals also showed that only half were aware of diet as part of lifestyle guidelines for people living with and beyond a cancer diagnosis and after completing treatment [16].

Given these findings, there is an urgent need to engage a wide range of HCPs who provide nutritional care and advice for people living with and beyond cancer [17]. In response, the National Institute for Health Research (NIHR) Cancer and Nutrition Collaboration (http://cancerandnutrition.nihr.ac.uk) developed a national UK survey of healthcare professionals to investigate the breadth and diversity of practice. For the purpose of this survey, people diagnosed with cancer were referred to as cancer patients. This paper presents the survey's findings that aimed to examine the provision of nutrition information by HCPs, their confidence in providing nutritional advice and their awareness of guidelines. It also investigates the training needs of HCPs to inform a future strategic framework for nutrition education and training on nutrition and cancer. Other aspects considered in the survey with respect to assessment of nutritional status and tools used in practice will be presented in a separate paper.

\section{Methods}

\section{Survey development and measures}

A multidisciplinary professional working group was established from known members of the NIHR Cancer and Nutrition collaboration toolkit and professionals work streams to develop the survey tool. The survey component identification included HCP delivery of nutrition information and forms of information sharing, education and confidence in nutrition knowledge and perceived training requirements. Initial survey queries were compiled by a subgroup of toolkit members and circulated to the working group for review. Members assessed questions for clinical and scientific relevance, question construct/interpretation and response variable accuracy. This was done over two teleconferences, and additional comments were taken via email after both meetings. The survey was then piloted with a group of five oncology dietitians and two surgeons from a local hospital. Several oncologists and nurses were also contacted, but a response was not received. Piloting allowed a realistic estimate of time-to-complete, response rate and flagged a small number of ambiguities, which were corrected prior to implementation.

The final 21-item online questionnaire included queries on nutrition assessment and monitoring as well as education/ training needs. Here, we report on only the education, training and information provision of HCP (Table 1). The completed survey used mixed response variables including Likert scales, single and multiple responses along with open-ended queries. The final questions were exported to iSurvey, a survey tool of Southampton University.

\section{Participants}

The online survey was disseminated to HCPs, with a followup reminder via professional groups, networks and personal contacts, including the British Dietetic Association, Royal College of Nursing, UK Oncology Nursing Society, British Association of Surgical Oncology/Association for Cancer Surgery, Royal College of General Practitioners, British Association of Head and Neck Oncologists, British Psychosocial Oncology Society, Royal College of Speech and Language Therapists and NIHR Office for Clinical Research Infrastructure. A pragmatic view was taken on sample size (as no data or precedents are available) and sought to achieve 100 responses from each professional group 
Table 1 Reported survey queries relating to nutrition education, information provision and training needs of healthcare professionals

\begin{tabular}{|c|c|c|c|c|}
\hline Topic & Survey question & Responses & Sub-question & Responses \\
\hline \multirow[t]{3}{*}{$\begin{array}{l}\text { Provision of nutrition } \\
\text { advice }\end{array}$} & $\begin{array}{c}\text { Do you provide information on } \\
\text { nutrition to cancer patients? }\end{array}$ & Yes & $\begin{array}{l}\text { What do you } \\
\text { provide? }\end{array}$ & $\begin{array}{l}\text { Locally produced leaflets/verbal advice/- } \\
\text { nationally produced leaflets/website/- } \\
\text { others (free text) }\end{array}$ \\
\hline & & No & & \\
\hline & $\begin{array}{l}\text { How confident do you feel in } \\
\text { providing nutritional advice } \\
\text { to cancer patients? }\end{array}$ & $\begin{array}{l}\text { Not at all confident/not very } \\
\text { confident/neutral/- } \\
\text { somewhat } \\
\text { confident/completely con- } \\
\text { fident }\end{array}$ & & \\
\hline \multirow[t]{2}{*}{$\begin{array}{l}\text { Awareness of } \\
\text { guidelines }\end{array}$} & $\begin{array}{l}\text { Are you aware of any guidelines } \\
\text { for nutritional advice for } \\
\text { cancer patients? }\end{array}$ & Yes & $\begin{array}{l}\text { What do you use } \\
\text { and where } \\
\text { does it come } \\
\text { from? }\end{array}$ & Free text \\
\hline & & No & & \\
\hline \multirow[t]{5}{*}{ Training in nutrition } & $\begin{array}{l}\text { Have you ever received training } \\
\text { on nutritional care for cancer } \\
\text { patients? }\end{array}$ & Yes & $\begin{array}{l}\text { What type of } \\
\text { training and } \\
\text { how long ago? }\end{array}$ & Free text \\
\hline & & No & & \\
\hline & $\begin{array}{l}\text { Do you feel that you need } \\
\text { further training in relation to } \\
\text { nutritional care of cancer } \\
\text { patients? }\end{array}$ & Yes & $\begin{array}{l}\text { What training } \\
\text { would } \\
\text { specifically } \\
\text { benefit your } \\
\text { clinical } \\
\text { practice? }\end{array}$ & $\begin{array}{l}\text { Assessment of nutrition status/artificial } \\
\text { feeding/supplements/dietary advice for } \\
\text { specific cancer site or stage/physical } \\
\text { activity assessment/evidence for alter- } \\
\text { native dietary approaches/other }\end{array}$ \\
\hline & & No & & \\
\hline & $\begin{array}{l}\text { Which methods of training } \\
\text { delivery do you prefer?' }\end{array}$ & $\begin{array}{l}\text { Face-to-face/conference or } \\
\text { study } \\
\text { day/e-learning/webinars/- } \\
\text { other }\end{array}$ & & \\
\hline GP specific questions & $\begin{array}{l}\text { Do you feel GPs have a role to } \\
\text { play in supporting the } \\
\text { nutritional needs of patients } \\
\text { living with and beyond } \\
\text { cancer? }\end{array}$ & Free text & & \\
\hline
\end{tabular}

(physicians and surgeons; dietitians; nurses; speech and language therapists; other). Data were collected anonymously between June 2016 and May 2017.

\section{Ethical statement}

The Research Governance and Quality Assurance Manager from University Hospitals Southampton NHS Foundation Trust's R\&D team confirmed that ethics approval was not considered necessary as the survey was anonymous and did not include any personal information about the participants. Participants consented to take part in the survey by ticking a relevant box on the first page of the survey.

\section{Statistical analysis}

Responses were downloaded from iSurvey to Excel and subsequently imported to SPSS (v23.0, Chicago, IL, USA) for analysis. Descriptive statistical analysis (numbers and percentages) was generated to determine the proportion of respondents who discussed nutrition, confidence in providing nutritional advice, an awareness guidelines, had received training, perceived need for training, areas for training that would support practice as well as the preferred platform of training. Descriptive analyses were carried out using the crosstabs function. As the 'other' represented a number of different HCP groups, it was not included in the analysis. Chi square tests were used to assess whether there were associations between the professional groups. Significance was established at $p=0.05$

\section{Results}

\section{Responses}

There were 610 responses of which there were $191(31 \%)$ nurses (oncology and general), 152 (25\%) dietitians (oncology and general) and 187 (31\%) doctors (primary care and 
surgeons/hospital specialists), and of these 79 (13\%) were GPs, 54 (9\%) speech and language therapists (SLTs) and 26 from 'other' groups that included physiotherapists, radiographers, pharmacists and psychologists (Table 2). As the latter group was excluded from analyses, this left a sample of 584 responses. Among those who responded, the HCPs worked with a range of different cancer types. The majority of oncology dietitians specialised in head and neck (42\%) and upper GI $(43 \%)$ cancers, whilst most of the SLTs are specialised in head and neck cancer $(75 \%)$. Some HCPs specialised in more than one cancer site. The response rate is not known as the survey was sent out to a range of organisations with a wide range of members in addition to existing contacts.

\section{Discussion of nutrition}

Overall, 94\% ( $n=553)$ of HCPs discuss nutrition always or sometimes with their patients. All general and oncology dietitians and SLTs discuss nutrition; almost all oncology nurses (97.3\%) and general nurses $(95.3 \%)$ and doctors $(92.6 \%)$ discuss nutrition but proportionately fewer GPs $(82.3 \%)$ than other HCP groups $\left(\chi^{2}=42.02, \mathrm{df}=6, p=0.001\right)$ Fig. 1$)$.

Overall, $77 \%(n=446)$ of HCPs provide cancer patients with information on nutrition. As expected, all oncology dietitians provide information, and $94 \%$ of general dietitians provide information. Proportionately fewer GPs $(n=38,48.1 \%)$ provide information compared with other HCP groups $\left(\chi^{2}=\right.$ 117.0, $\mathrm{df}=6, p=0.001$ ).

Overall, $63.2 \%$ of HCPs provide verbal advice, $43.5 \%$ provide local leaflets, $40.5 \%$ provide national leaflets, and $16.8 \%$ provide information about a website. Proportionately, more oncology dietitians (98.9\%), general dietitians (79.0\%), oncology nurses $(68.9 \%)$ and general nurses $(60.5 \%)$ provide verbal advice in comparison with doctors $(48.1 \%)$, SLTs $(44.4 \%)$ and GPs $(38 \%)\left(\chi^{2}=89.78, \mathrm{df}=6, p=0.001\right)$. Significantly similar patterns were found for providing local $\left(\chi^{2}=171.53, \mathrm{df}=6, p=0.001\right)$ and national leaflets $\left(\chi^{2}=\right.$ $168.77, \mathrm{df}=6, p=0.001)$, with fewer GPs $(10.1 \%$ and $7.6 \%$, respectively) providing these in comparison with other HCPs.

\section{Awareness of guidelines}

As a group, 39\% $(n=226)$ of the HCPs reported being aware of nutritional guidelines for cancer patients (Fig. 2). Guidelines which were used included Macmillan Cancer Charity (26\%), National Institute for Health and Care Excellence (NICE) (25\%), European Society for Parenteral and Enteral Nutrition (ESPEN) guidelines (18\%), British Dietetic Association (BDA) (10\%) and World Cancer Research Fund (WCRF) (8\%), as well as guidelines for specific cancer types, e.g. Prostate Cancer UK, Clinical Oncology
Table 2 Numbers of respondents from the professional groups

\begin{tabular}{ll}
\hline Professional group & $N(\%)$ \\
\hline Nurse (oncology) & $148(24)$ \\
Nurse (general) & $43(7)$ \\
Dietitian (oncology) & $98(16)$ \\
Dietitian (general) & $54(9)$ \\
Doctor (secondary and tertiary settings) & $108(18)$ \\
GP & $79(13)$ \\
Speech and language therapy & $54(9)$ \\
Other & $26(4)$ \\
Total & 610 \\
\hline
\end{tabular}

Society of Australia (COSA) Head and Neck guidelines $(18 \%)$ and other guidelines including local Trust policy guidelines. Proportionately more oncology dietitians $(43.4 \%)$ used NICE $\left(\chi^{2}=47.06, \mathrm{df}=6, p=0.001\right)$ and ESPEN guidelines $\left(39.8 \% ; \chi^{2}=36.62 \mathrm{df}=6, p=0.001\right)$, and both oncology and general dietitians used BDA guidelines $\left(18.1 \%\right.$ and $19.0 \%$ respectively, $\chi^{2}=18.92, \mathrm{df}=6$, $p=0.001)$ in comparison with other HCP groups. In contrast, proportionately more oncology nurses used Macmillan information $\left(\chi^{2}=33.34, \mathrm{df}=6, p=0.001\right)$ in comparison with other groups.

Surprisingly not all of oncology dietitians (85\%) and general dietitians $(71 \%)$ were aware of guidelines. However only $25 \%$ of doctors, $30 \%$ of nurses, $25 \%$ of SLTs and $9 \%$ of GPs had an awareness of guidelines $\left(\chi^{2}=156.35, \mathrm{df}=6\right.$, $p=0.001$ ) (Fig. 1). Significantly more HCPs who were aware of the guidelines were found to be completely confident in providing nutritional advice $\left(n=100,44.4 \% ; \chi^{2}=149.50\right.$, $\mathrm{df}=4, p=0.001)$ and to always discuss nutrition with their patients $\left(n=177,79.0 \% ; \chi^{2}=79.28, \mathrm{df}=3, p=0.001\right)$.

\section{Nutrition training}

Among those that responded, $87 \%$ of oncology dietitians and $67 \%$ of general dietitians reported having received training for nutritional care for cancer patients. In contrast, $21 \%$ of oncology nurses, $28 \%$ of general nurses and only $15 \%$ of doctors and $9 \%$ of GPs had received nutrition training (Fig. 2). More than twothirds of HCPs who had received training were aware of nutrition guidelines $\left(n=132,67.3 \% ; \chi^{2}=101.28, \mathrm{df}=2, p=0.001\right)$.

As expected, oncology and general dietitians all have a degree or PG diploma in nutrition. About two-thirds of oncology and general dietitians report keeping clinically updated through training such as ESPEN, BAPEN, Parenteral and Enteral Nutrition Group (PENG), Malnutrition Universal Screening Tool 'MUST' training, BDA training and other Continued Professional Development (CPD) courses, through local trust training, reading journals and attending conferences. In contrast, a quarter of oncology nurses reported either 
Fig. 1 Proportion of respondents by professional group who discussed nutrition, had an awareness of guidelines and received relevant nutrition training

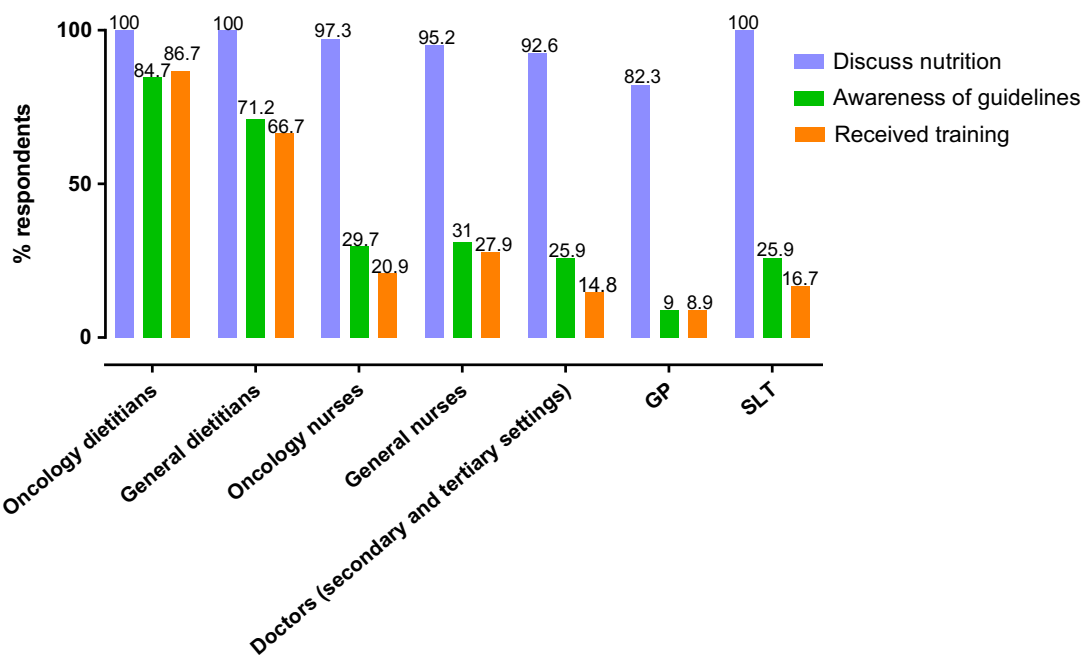

'MUST' training, in-house training and training via a CPD course. Three doctors pursed a formal qualification in nutrition, and two had formal ESPEN or 'MUST' training. Seven GPs reported 'MUST' training, and four taught themselves to use 'MUST' screening.

Fig. 2 Levels of confidence in providing nutritional advice for each professional group (\% respondents)

\section{Confidence in providing nutritional advice and perceived need for training}

Overall, $20.4 \%$ and $35.4 \%$ of all HCPs reported feeling completely or somewhat confident in providing nutritional

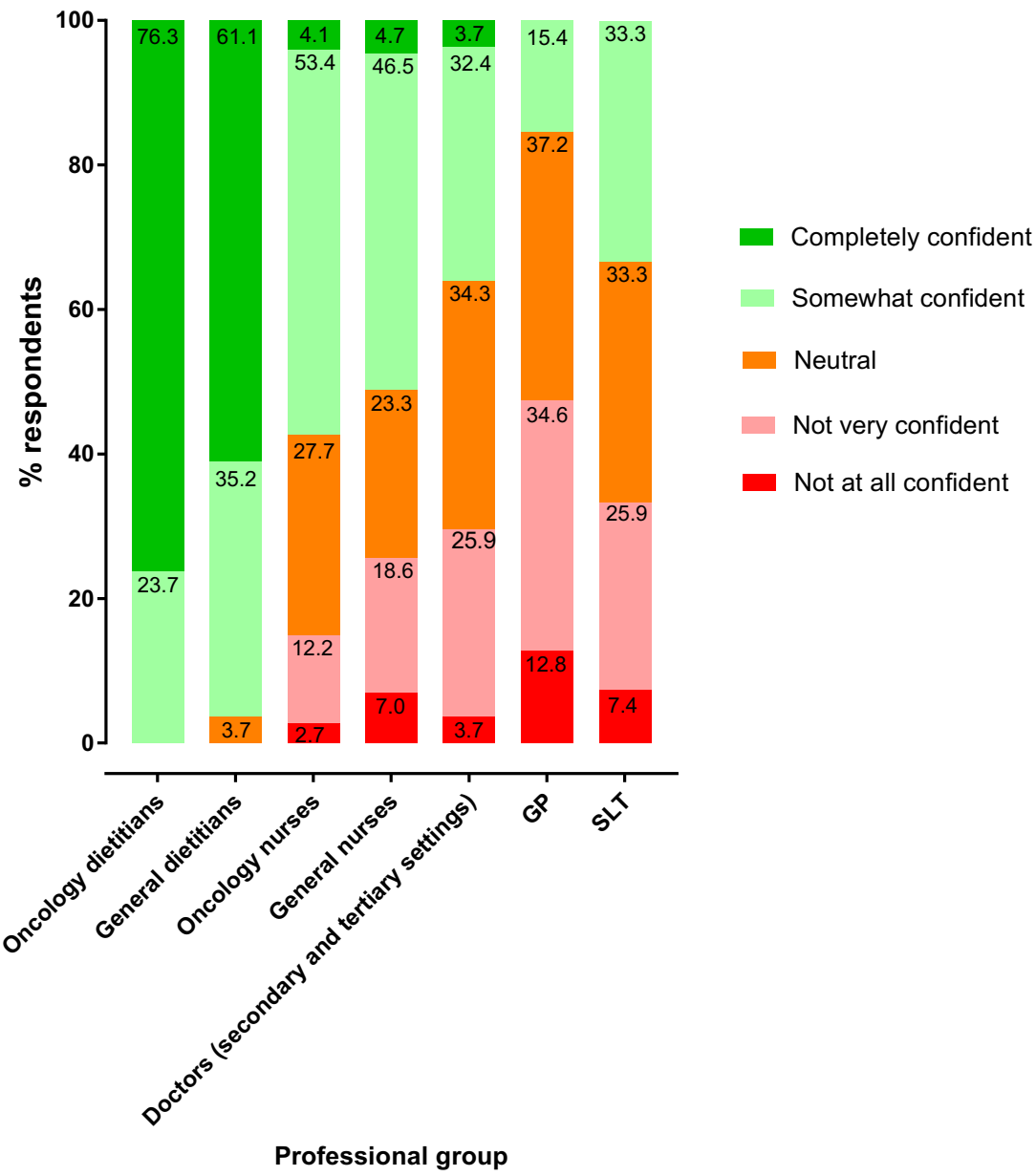


advice (Fig. 2). Both oncology and general dietitians were most confident $(76.3 \%$ and $61.1 \%$, respectively) or somewhat confident (23.7\% and $35.2 \%$, respectively). Only $3.7 \%$ and $32.4 \%$ of doctors were completely or somewhat confident in providing nutritional advice. Among oncology nurses, 53.4\% weresomewhat confident, but only $4.1 \%$ were completely confident. Only $15.4 \%$ of GPs were somewhat confident, and none was completely confident. Significantly more HCPs who were aware of guidelines were found to be completely confident in providing nutritional advice $(n=$ $\left.100,44.4 \% ; \chi^{2}=149.50, \mathrm{df}=4, p=0.001\right)$.

The majority $(64.6 \%, n=376)$ of HCPs said they have a need for training on nutritional care for cancer patients. Proportionately, more respondents who said they were not very confident, or somewhat confident in providing nutritional advice, wanted training $(n=18,75.0 \%$ and $n=144,69.9 \%$, respectively; $\left.\chi^{2}=59.32, \mathrm{df}=4, p=0.001\right)$. Similarly, proportionately more HCPs who had no awareness of guidelines awareness wanted training ( $n=243,68.6 \% ; \chi^{2}=6.53, \mathrm{df}=1, p=0.05$ ). The greatest need was reported by oncology and general nurses $(81 \%)$. There were $56 \%$ of doctors and $81 \%$ of GPs with reported needs for further training as well as $46 \%$ of oncology dietitians and $52 \%$ of general dietitians. Overall for the professional groups, the identified areas for further training were in order of rank: dietary advice for specific cancer site/stage (70\%), assessment of nutrition status (63\%), evidence for alternative dietary approaches $(57 \%)$ and dietary supplements $(47 \%)$. The preferred approach to provide training was conference/study days $(n=$ $399 ; 68 \%)$, face-to-face training $(n=340 ; 58 \%)$ and e-learning $(n=302 ; 52 \%)$ rather than webinars $(n=67 ; 11 \%)$.

Of the 79 GP responses, there were 73 (95\%) who considered that GPs have a role to play in supporting the nutritional needs of people living with and beyond cancer. The reasons for their responses were because GPs are the first point of call for patients; they know the patient well, are easily accessible and trusted by the patients, provide a holistic approach to care that includes nutrition and have the responsibility of giving correct information when asked by the patient. Four GPs felt that they did not have a role in supporting nutritional care. They attributed this to existing time constraints on GPs and that they could not be expected to be an expert on everything.

\section{Discussion}

The present study is the largest UK survey that has specifically investigated the provision of nutrition for cancer patients across a wider range of HCP groups. The findings have shown that the majority of HCPs appears to discuss nutrition with their cancer patients, aligning with previous surveys of nutrition support provided by oncologists [13] and for other HCPs where diet was part of lifestyle guidance [16]. Awareness of guidelines varied ranging from using national guidelines and those for specific cancer types of just using utilising trusted sources of guidance.

However, the discussion of nutrition was related to the awareness of guidelines for cancer patients. The awareness of guidelines varied between the different professional groups with most, but not all dietitians having the greatest awareness of guidelines and GPs reporting the least. Those HCPs with a greater awareness of guidelines had received training and were found to be completely confident in providing nutritional advice. Not surprisingly, dietitians were most confident in providing nutritional advice to cancer patients than the other HCP groups, but there were still a fifth of dietitians who were not completely confident. A lack of sufficient time within routine NHS consultations to provide nutritional advice was reported by GPs. Other barriers to providing nutritional advice by HCPs could be attributed to a perceived lack of evidence for the benefit of nutrition interventions, inadequate knowledge and concerns whether the patient is ready and open to receive such advice as well as lack of time [12, 15-18].

Given these reported barriers by HCPs to providing advice, the present study has shown the perceived need for training in the provision of nutritional care for cancer patients across all the professional groups including about half of dietitians but for the majority of nurses, doctors and particularly GPs. The most common aspects that HCPs identified were dietary advice for specific cancer and cancer stage, assessment of nutritional status, alternative dietary approaches and dietary supplements. Thus, education and training in these areas are needed to ensure that cancer patients receive appropriate and consistent advice on nutrition. Consideration should also be given to the way in which education and training are delivered. It should reflect the challenges that HCPs might experience including cost and protected time for continued professional development $[8,19,20]$. In the present study, the preferred platform of training was equally distributed across face-toface training, conference/study days and E-learning/ Webinars. This indicates that both the content and a blended approach to learning should be considered to inform the future design of education and training.

A potential limitation of this study is that the respondents were members of professional organisations and who already may have had an interest in nutrition and more likely to respond. As such this could limit the generalisability of the findings. It was also not possible to determine the exact response rate so may not be representative of all HCPs. However, the proportion of respondents from each professional group was similar for nurses, dietitians and doctors who worked across a range of different cancer specialisms in the UK. More research is needed to explore the potential contribution and role of other HCPs groups that were under- 
represented in the present study. It would appear that the various professional groups responded differently to the question for awareness of guidelines that included nutritional guidelines as well as sources representing nutritional guidance and information. Further research could explore this aspect with more clarity.

\section{Conclusions}

These findings demonstrate that whilst HCPs provide information on nutrition, awareness of guidelines and confidence in providing nutritional advice are variable. It is important that cancer patients receive consistent evidencebased advice on nutrition from HCPs that is tailored to suit the type and stage of cancer treatment. All HCPs should have access to appropriate nutrition education and training, to improve their knowledge and confidence in providing advice and ensure consistency in practice for quality improvements in patient care. However, it is recognised that there remains a need for more highquality nutrition research to inform the evidence base to enable HCPs provide appropriate nutritional advice to support cancer care.

Acknowledgements The authors acknowledge the contribution of all the participants in the study. The contribution of the following people are also acknowledged: Millie Barrett, Marie Cantwell, Bernard Corfe, Mhairi Donald, Lucy Eldridge, Jacqui Gath, Carol Granger, Vanessa Halliday, Victoria Lyamide Nnatuanya, Megan Lloyd, Jill Scott, Clare Shaw, Martin Wiseman, Theresa Wiseman, Stephen Wootton and Catherine Zollman - on behalf of the 'creating a skilled community practice' and 'characterising nutritional status in cancer' work streams of the National Institute for Health Research (NIHR) Cancer and Nutrition Collaboration.

Authors' contribution JM, FM and FD drafted the manuscript. FM and $\mathrm{JM}$ conducted the analysis and interpreted the data. LM, RC, RW, ML, JR, CG, SB and LT conceived and contributed to the design of the study. LT provided input from the patient perspective. All of the authors have no conflicts of interest to declare.

\section{Compliance with ethical standards}

Conflict of interest The authors declare that they have no conflict of interest.

Ethical approval The Research Governance and Quality Assurance Manager from University Hospitals Southampton NHS Foundation Trust's R\&D team confirmed that ethics approval was not considered necessary as the survey was anonymous and did not include any personal information about the participants. Participants consented to take part in the survey by ticking a relevant box on the first page of the survey.
Open Access This article is licensed under a Creative Commons Attribution 4.0 International License, which permits use, sharing, adaptation, distribution and reproduction in any medium or format, as long as you give appropriate credit to the original author(s) and the source, provide a link to the Creative Commons licence, and indicate if changes were made. The images or other third party material in this article are included in the article's Creative Commons licence, unless indicated otherwise in a credit line to the material. If material is not included in the article's Creative Commons licence and your intended use is not permitted by statutory regulation or exceeds the permitted use, you will need to obtain permission directly from the copyright holder. To view a copy of this licence, visit http://creativecommons.org/licenses/by/4.0/.

\section{References}

1. Davies NJ, Batehup L, Thomas R (2011) The role of diet and physical activity in breast, colorectal, and prostate cancer survivorship: a review of the literature. Br J Cancer 105:S52-S73. https:// doi.org/10.1038/bjc.2011.423

2. World Cancer Research Fund and American Institute for Cancer Research (2007) Food, nutrition, physical activity, and the prevention of cancer: a global perspective. AICR, Washington DC

3. Maddams J, Utley M, Møller H (2012) Projections of cancer prevalence in the United Kingdom, 2010-2040. Br J Cancer 107(7): 1195-1202. https://doi.org/10.1038/bjc.2012.366

4. NHS England. Achieving world class outcomes: a strategy for England 2015-2020. Available from: https://www.england.nhs. uk/wp-content/uploads/2017/10/national-cancer-transformationprogramme-2016-17-progress.pdf. Accessed 17 Aug 2020

5. Arends J, Bachmann P, Baracos V, Barthelemy N, Bertz H, Bozzetti F, Fearon K, Hütterer E, Isenring E, Kaasa S, Krznaric Z, Laird B, Larsson M, Laviano A, Mühlebach S, Muscaritoli M, Oldervoll L, Ravasco P, Solheim T, Strasser F, de van der Schueren M, Preiser JC (2017) ESPEN guidelines on nutrition in cancer patients. Clin Nutr 36(1):11-48. https://doi.org/10.1016/j.clnu. 2016.07.015

6. Demark-Wahnefried W, Peterson B, McBride C, Lipkus I, Clipp E (2000) Current health behaviors and readiness to pursue lifestyle changes among men and women diagnosed with early stage prostate and breast carcinomas. Cancer 88(3):674-684

7. Gavazzi C, Sieri S, Traclò F, Sproviero A, Vandoni G, Ricci R, Stragliotto S, Zagonel V (2018) Changes in food habits in cancer patients in Italy: a survey. AIOM - SINPE FAVO. Nutrition 55-56:140-145. https://doi.org/10.1016/j. nut.2018.04.002

8. Murphy JL, Girot EA (2013) The importance of nutrition, diet and lifestyle advice for cancer survivors - the role of nursing staff and interprofessional workers. J Clin Nurs 22(11-12):1539-1154. https://doi.org/10.1111/jocn.12053

9. Beeken RJ, Williams K, Wardle J, Croker H (2016) "What about diet?" A qualitative study of cancer survivors' views on diet and cancer and their sources of information. Eur J Cancer Care 25(5): 774-783. https://doi.org/10.1111/ecc.12529

10. Kassianos AP, Coyle A, Raats MM (2015) Perceived influences on post-diagnostic dietary change among a group of men with prostate cancer. Eur J Cancer Care 24(6):818-826. https://doi.org/10.1111/ ecc. 12357 
11. Hardcastle SJ, Maxwell-Smith C, Hagger MS, O-Connor M, Platell C (2018) Exploration of information and support needs in relation to health concerns, diet and physical activity in colorectal cancer survivors. Eur J Cancer Care 27(1):e12679. https://doi.org/10.1111/ ecc. 12679

12. Sutton E, Hackshaw-McGeagh LE, Aning J, Bahl A, Koupparis A, Persad R, Martin RM, Lane JA (2017) The provision of dietary and physical activity advice for men diagnosed with prostate cancer: a qualitative study of the experiences and views of health care professionals, patients and partners. Cancer Causes Control 28(4):319-329. https:// doi.org/10.1007/s10552-017-0861-7

13. Spiro A, Baldwin C, Patterson A, Thomas J, Andreyev HJ (2006) The views and practice of oncologists towards nutritional support in patients receiving chemotherapy. Br J Cancer 95:431-434. https:// doi.org/10.1038/sj.bjc.6603280

14. Martin L, de van der Schueren MA, Blauwhoff-Buskermolen S, Baracos V, Gramlich L (2016) Identifying the barriers and enablers to nutrition care in head and neck and esophageal cancers: an international qualitative study. J Parenter Enter Nutr 40(3):355-366. https://doi.org/10.1177/0148607114552847

15. Caccialanza R, Cereda E, Pinto C, Cotogni P, Farina G, Gavazzi C, Gandini C, Nardi M, Zagonel V, Pedrazzoli P (2016) Awareness and consideration of malnutrition among oncologists: insights from an exploratory survey. Nutrition 32(9):1028-1032. https://doi.org/ 10.1016/j.nut.2016.02.005

16. Williams K, Beeken RJ, Fisher A, Wardle J (2015) Health professionals' provision of lifestyle advice in the oncology context in the United Kingdom. Eur J Cancer Care 24(4):522-530. https://doi. org/10.1111/ecc. 12305
17. Rauh S, Antonuzzo A, Bossi P, Eckert R, Fallon M, Fröbe A, Karamouzis M, Lakatos G, Molitor JL (2018) Nutrition in patients with cancer: a new area for medical oncologists? A practising oncologist's interdisciplinary position paper. ESMO Open 3(5): e000345. https://doi.org/10.1136/esmoopen-2018-000345

18. van Veen MR (2019) Improving information provision on nutrition and cancer: for cancer survivors and health professionals. $\mathrm{PhD}$ thesis, Wageningen University, Wageningen, The Netherlands

19. Murphy J, Worswick L, Pulman A, Ford G, Jeffery J (2015) Translating research into practice: evaluation of an e-learning resource for health care professionals to provide nutrition advice and support for cancer survivors. Nurse Educ Today 35(1):271e6. https://doi.org/10.1016/j.nedt.2014.05.009

20. Klemp JR, Frazier LM, Glennon C, Trunecek J, Irwin M (2011) Improving cancer survivorship care: oncology nurses' educational needs and preferred methods of learning. J Cancer Educ 26:234-242. https://doi.org/10.1007/s13187011-0193-3

This work was designed and conducted by members of the NIHR Cancer and Nutrition Collaboration. The views expressed are those of the author(s) and not necessarily those of the NIHR or the Department of Health and Social Care.

Publisher's note Springer Nature remains neutral with regard to jurisdictional claims in published maps and institutional affiliations. 